\title{
CORRESPONDENCE
}

\section{STRAIGHT ON TO KASPAROV}

\author{
David Levy
}

\section{London, England}

In my article "When Will Brute Force Programs Beat Kasparov?" (ICCA Journal, Vol. 9, No. 2, pp. 81-87), I showed a least-squares best-fit straight line with the equation: rating $=49.2 \times$ (year -1900$)-1697$. At that time, I made the assumption that the USCF rating scale and the international Elo scale were the same at the top level and showed that, with this assumption, a lower bound on the year when a program could first beat Kasparov was 1990.

In the 1991 book How Computers Play Chess (D. Levy and M. Newborn, Computer Science Press), I presented the same data but without the false assumption that the two rating scales were the same at the top, and extrapolated to predict a computer performance of 2911 or better (USCF scale) in the year 1994. This is the performance needed to win a 24-game match (i.e., a World-Championship match) against Kasparov playing at his 1991 rating.

As we have recently seen, in 1994 a computer program (Fritz3) has achieved a performance rating of 2803 on the international scale, equivalent to approximately 2903 on the USCF scale. Not only that, but 1994 has turned out to be the year in which a program first beat Kasparov in a tournament game (albeit a speed tournament). So with the caveat that one game in a speed tournament is hardly the same thing as a match for the World Championship, we can say that the result in Munich endorses earlier predictions to some extent at least.

There will be those Grandmasters who lull themselves into a false sense of security that at 40 moves in 2 hours the World Championship is still completely safe in human hands. But what happens when a program even stronger than Fritz3 competes on a system with not just one Pentium chip but a thousand or more?

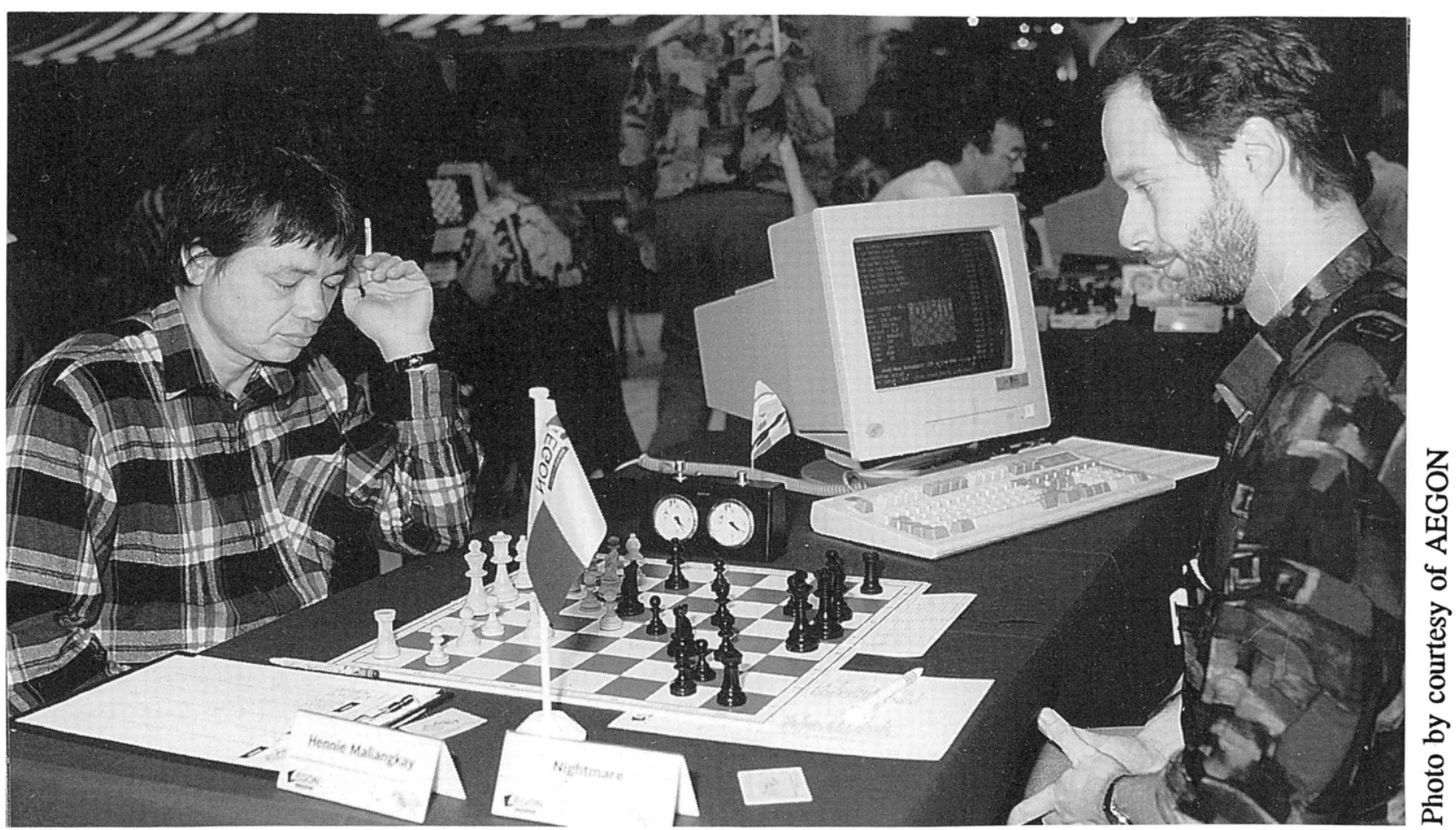

FACING ONE'S NIGHTMARE

Henny Maliangkay (l) - opposed to spooks

as programmed by Rainer Gellner.

(Round 1, AEGON tournament 1994, The Hague) 